\title{
VULNERABILIDADE NA ADESÃO À PROFILAXIA DA TRANSMISSÃO VERTICAL DO HIV*
}

Tassiane Ferreira Langendorf ${ }^{1}$,Stela Maris de Mello Padoin ${ }^{2}$,Cristiane Cardoso de Paula ${ }^{3}$, Clarissa Bohrer da Silva ${ }^{4}$

RESUMO: Objetivou-se avaliar as evidências disponíveis nos artigos científicos sobre fatores que influenciam na adesão à profilaxia da transmissão vertical do vírus da imunodeficiência humana. Esta revisão integrativa foi desenvolvida nas bases de dados LILACS e MEDLINE, com recorte temporal de 1994-2010; 29 artigos foram submetidos à análise de conteúdo temática, com categorização teórica segundo o referencial de vulnerabilidade. Os resultados apontam que, no plano individual, as mulheres tomam decisões que refletem, positiva ou negativamente, na adesão; no plano social se evidencia a dificuldade de acesso à informações. No plano programático tem-se a necessidade de formação/qualificação profissional para assistência aliada às políticas púbicas; os planos de vulnerabilidade mantêm estreita relação entre si. Tem-se como possibilidade a mediação, pelo enfermeiro, das informações entre os planos programático e individual por meio da educação em saúde, viabilizando a decisão informada quanto aos cuidados de saúde na profilaxia da transmissão vertical do vírus.

PALAVRAS-CHAVE: Vulnerabilidade; Transmissão vertical de doença infecciosa; HIV; Síndrome da imunodeficiência adquirida; Enfermagem.

\section{VULNERABILITY IN ADHERENCE TO PROPHYLAXIS OF VERTICAL TRANSMISSION OF HIV}

ABSTRACT: This integrative review aimed to evaluate the evidence available in scientific articles on factors which influence the adherence to prophylaxis of vertical transmission of the Human Immunodeficiency Virus (HIV). It was developed in the LILACS and MEDLINE databases with time cut-off points of 1994-2010; 29 articles were submitted to thematic content analysis, with theoretical categorization according to the framework of vulnerability. The results indicate that, on an individual plane, the women take decisions which reflect positively or negatively on adherence; on the social plane, difficulty in accessing information is evidenced. In the programmatic plane there is the need for professional training/qualification for care, combined with public policies; the planes of vulnerability maintain a close relationship with each other. There is the possibility of mediation, by the nurse, of information between the programmatic plans and the individual, through health education, viabilizing informed decisions relating to health care in prophylaxis of vertical transmission of the virus.

KEYWORDS: Vulnerability; Vertical transmission of infectious disease; HIV; Acquired immunodeficiency syndrome; Nursing.

\section{VULNERABILIDAD EN LA ADHESIÓN A LA PROFILAXIA DE LA TRANSMISIÓN VERTICAL DEL HIV}

RESUMEN: El objetivo del estudio fue evaluar las evidencias disponibles en los artículos científicos sobre factores que influencían en la adhesión a la profilaxia de la transmisión vertical del virus de la inmunodeficiencia humana. Esta revisión integrativa fue desarrollada en las bases de datos LILACS y MEDLINE, con enfoque temporal de 1994-2010; 29 artículos fueron sometidos al análisis de contenido temático, con categorización teórica de acuerdo con el referencial de vulnerabilidad. Los resultados apuntan que, en el plan individual, las mujeres toman decisiones que tienen consecuencias positivas o negativas en la adhesión; en el plan social, se evidencía la dificultad de acceso a las informaciones. En el plan programático, hay la necesidad de formación/cualificación profesional para asistencia junto a las políticas públicas; los planos de vulnerabilidade mantienen íntima conexión entre sí. Se mira como posibilidad la mediación, por el enfermero, de las informaciones entre los planos programático e individual por medio de la educación en salud, viabilizando la decisión informada cuanto a los cuidados de salud en la profilaxia de la transmisión vertical del virus.

PALABRAS CLAVE: Vulnerabilidad; Transmisión vertical de enfermedad infecciosa; HIV; Síndrome de la inmunodeficiência adquirida; Enfermería.

\footnotetext{
${ }^{1}$ Enfermeira. Mestre em Enfermagem. Doutorando pela Escola de Enfermagem Anna Nery da Universidade Federal do Rio de Janeiro. Membro do Grupo de Pesquisa Cuidado à Saúde das Pessoas, Famílias e Sociedade da Universidade Federal de Santa Maria - UFSM. ${ }^{2}$ Enfermeira. Doutora em Enfermagem. Professora do Departamento e do Programa de Pós-Graduação em Enfermagem da UFSM. Líder do Grupo de Pesquisa Cuidado à Saúde das Pessoas, Famílias e Sociedade.

${ }^{3}$ Enfermeira. Doutora em Enfermagem. Professora do Departamento e do Programa de Pós-Graduação em Enfermagem da UFSM. Membro do Grupo de Pesquisa Cuidado à Saúde das Pessoas, Famílias e Sociedade.

${ }^{4}$ Enfermeira. Membro do Grupo de Pesquisa Cuidado à Saúde das Pessoas, Famílias e Sociedade.
}

Autor correspondente:

Tassiane Ferreira Langendorf

Universidade Federal de Santa Maria

Av. Roraima, 1000 - 97105-900 - Santa Maria-RS-Brasil

Email: tassi.lang@gmail.com
Recebido: 09/01/2012

Aprovado: 29/05/2012

Cogitare Enferm. 2012 Out/Dez; 17(4):758-66 


\section{INTRODUÇÃO}

No Brasil, a prevalência de infecção pelo vírus da imunodeficiência humana (HIV) se apresenta em 0,6\% na população de 15 a 49 anos de idade, onde $0,4 \%$ são mulheres. Entre os anos 2000 e 2009 foram notificados 54.218 casos de infecção pelo HIV em gestantes, das quais $40.999(75,6 \%)$ se concentram nas Regiões Sul e Sudeste ${ }^{(1)}$.

A política nacional adotou o protocolo AIDS Clinical Trials Group 076 (em 1994) como estratégia eficaz na redução da transmissão vertical (TV). Tal protocolo estabeleceu o uso da Zidovudina (AZT) na gestação, durante o parto e nas seis primeiras semanas de vida do bebê $\hat{e}^{(2)} \mathrm{e}$, atualmente, soma-se às Recomendações para Profilaxia da Transmissão Vertical do HIV e Terapia Antirretroviral em Gestantes ${ }^{(3)}$.

O diagnóstico de soropositividade ao HIV demanda acompanhamento de saúde e adesão ao tratamento, os quais sofrem influência de diversos fatores. Dentre eles se destacam fatores do próprio indivíduo, da rede social e da assistência prestada à essa população $0^{(4)}$. Os fatores que se relacionam ao indivíduo estão ligados ao cotidiano das mulheres, às vivências, experiências, desafios e enfrentamentos do seu dia a dia. Podem ser observados no ambiente da família, da comunidade, do serviço de saúde ${ }^{(5)}$. No que tange ao social, as mulheres convivem com preconceito e discriminação, advindos dos diferentes meios sociais, inclusive da própria família. Para se protegerem desses eventos, estabelecem o silenciamento da sua condição sorológica e, dessa forma, a restrição de sua rede social de apoio. Isso pode implicar na adesão ao tratamento ${ }^{(6)}$.

$\mathrm{Na}$ assistência por equipe multiprofissional destaca-se o enfermeiro, que participa nas etapas da profilaxia no pré, peri e pós-natal. Amparado legalmente, realiza as consultas de enfermagem no pré-natal ${ }^{(7)}$, momento oportuno para o aconselhamento pré-teste, oferecer o teste anti-HIV e esclarecer as dúvidas com vistas à adesão a profilaxia.

Nesta perspectiva, tem-se como objetivo avaliar as evidências disponíveis nos artigos científicos sobre os fatores que influenciam na adesão à profilaxia da transmissão vertical do HIV.

\section{MÉTODO}

Foi realizada uma revisão integrativa ${ }^{(8)}$, que teve como questão norteadora da pesquisa: quais os fatores que influenciam na adesão para a profi- laxia da transmissão vertical do HIV? Para compor a amostragem, efetuou-se uma busca nas bases de dados Literatura Latino-Americana e do Caribe em Ciências da Saúde (LILACS) e National Library of Medicine (MEDLINE). O levantamento dos estudos ocorreu em maio de 2011. Utilizaram-se os termos ("sindrome da imunodeficiencia adquirida") or "hiv" [descritor de assunto] and ("vertical") or "materno-infantil") or "mae-filho") or "perinatal" [palavras] and ("tratamento") or ("terapia") or "profilaxia" [palavras]. Localizaram-se os quantitativos de 192 (LILACS) e 718 (MEDLINE) artigos.

Os critérios de inclusão foram: artigos de pesquisa; disponíveis na íntegra online; nos idiomas português, inglês ou espanhol. E como critérios de exclusão: artigos sem resumo na base de dados ou incompletos. O recorte temporal utilizado foi de 1994, em virtude do marco que instituiu o Protocolo de Prevenção da Transmissão Vertical, até 2010.

A seleção se desenvolveu por meio da leitura dos títulos e resumos, os quais foram submetidos aos critérios de inclusão e exclusão, totalizando 29 artigos. Foi desenvolvida análise temática de conteúdo ${ }^{(9)} \mathrm{com}$ categorização teórica dos estudos, ou seja, as unidades temáticas foram pré-estabelecidas por meio do referencial de vulnerabilidade ${ }^{(10)}$.

O conceito de vulnerabilidade pode ser entendido por considerar a possibilidade de exposição das pessoas à infecção pelo HIV e adoecimento como a resultante de um conjunto de aspectos individuais, coletivos e contextuais, que acarretam maior suscetibilidade e disponibilidade de recursos para se proteger. A vulnerabilidade procura examinar essa questão a partir de três planos analíticos inter-relacionados: o individual, o social e o programático ${ }^{(10)}$.

No plano individual, destaca os comportamentos que criam a oportunidade de infectar-se e/ou adoecer, nas situações de transmissão do HIV. Relaciona-se ao grau de consciência que esses indivíduos têm acerca dos possíveis danos decorrentes de tais comportamentos. O plano social refere-se às possibilidades de os indivíduos obterem acesso a informações e fazerem efetivo uso delas; ao acesso e qualidade dos serviços de saúde; aos aspectos sociopolíticos e culturais. O plano programático relaciona-se ao modo como os serviços de saúde e sociais, com destaque aqui para a educação, mobilizam os recursos para a prevenção à infecção pelo HIV e ao adoecimento. Refere-se ao grau e tipo de compromisso das autoridades locais que implicam em ações preventivas e assistenciais ${ }^{(10)}$. 


\section{RESULTADOS}

Neste estudo, no plano individual, se evidenciou nos fatores comportamentais a decisão de realizar ou não uma ação, como realizar o teste anti-HIV, o desafio na aceitação do diagnóstico, realizar o tratamento e amamentar (Tabela 1).

Evidencia-se que os fatores de vulnerabilidade relacionados ao plano social referem-se às distintas possibilidades de acesso a informações e à aplicabi- lidade destas pelas pessoas (Tabela 2). Dentre eles, destacam-se: a educação em saúde individual ou coletiva para as mulheres e seus parceiros; a escolaridade e a renda.

No plano programático os fatores se relacionam à articulação dos serviços de maneira que possibilite que as pessoas mobilizem recursos para prevenção da transmissão vertical do HIV (Tabela 3). Destacam-se: a formação profissional; a qualificação profissional; a qualidade do atendimento nos serviços de saúde.

Tabela 1 - Fatores relacionados à adesão à profilaxia da transmissão vertical do HIV e nexos com a vulnerabilidade no plano analítico individual. LILACS e MEDLINE, 1994-2010

Fatores abordados

\begin{tabular}{|c|c|}
\hline Fatores abordados & Fatores relacionados ao objeto de estudo \\
\hline \multirow{4}{*}{ Oferta do teste anti-HIV } & Mulheres não aceitam realizá-lo ${ }^{(11-12)}$ \\
\hline & Mulheres aceitam realizá-lo(13) \\
\hline & Consideram-se fora de risco para a infecção ${ }^{(14-15)}$ \\
\hline & $\begin{array}{l}\text { Não realizam o aconselhamento por medo do teste, porque o parceiro não con- } \\
\text { corda ou por ainda não se sentirem prontas }{ }^{(16)}\end{array}$ \\
\hline
\end{tabular}

Aceitação do diagnóstico

Dificuldade em aceitá-lo resulta na falta de iniciativa para realizar o tratamento para profilaxia ${ }^{(17)}$

Mulheres decidem não ingerir $\mathrm{ARV}^{*(18)}$

Mulheres aceitam ingerir ARV*(13)

Ingerem de maneira irregular ${ }^{(19)}$

Tratamento

Mãe decide não oferecer $\mathrm{ARV}^{*}$ para o bebê $\hat{e}^{(20)}$

Gravidez e bebê são estímulo e motivação para realizarem o tratamento(21-22)

Como mulheres não aderem ao tratamento, como mães sim ${ }^{(17)}$

\section{Possibilidade da transmissão por amamentação}

Mulheres decidem amamentar(19,23-24)

Mulheres evitam amamentar ${ }^{(13)}$

Medo de rejeição por não amamentar ${ }^{(25)}$

Fatores socioculturais e econômicos influenciam sobre a decisão de amamentar ${ }^{(19)}$ Realizam escolha informada ${ }^{(26-27)}$

*Antirretroviral

Tabela 2 - Fatores relacionados à adesão à profilaxia da transmissão vertical do HIV e nexos com a vulnerabilidade no plano analítico social. LILACS e MEDLINE, 1994-2010

\begin{tabular}{ll}
\hline \multicolumn{1}{c}{ Fatores abordados } & \multicolumn{1}{c}{ Fatores relacionados ao objeto de estudo } \\
\hline & $\begin{array}{l}\text { Pode contribuir para aceitação da realização do teste anti-HIV e aconselhamento }{ }^{(27-28)} \\
\text { Mulheres aceitam realizar o teste a partir da informação que recebem }\end{array}$ \\
Educação em saúde & $\begin{array}{l}\text { Mulheres obtêm informações sobre os benefícios da profilaxia } \\
\text { No pré e pós-natal, com assuntos sobre HIV e alimentação infantil, se pode contribuir } \\
\text { para maior adesão aos cuidados para profilaxia }\end{array}$ \\
\hline \multirow{2}{*}{ Escolaridade } & $\begin{array}{l}\text { Mulheres com menor escolaridade se recusam a realizar o teste anti-HIV } \\
\text { Influencia na decisão de amamentar ou não }{ }^{(32)}\end{array}$ \\
\hline \multirow{2}{*}{ Renda } & $\begin{array}{l}\text { Diante da carência econômica, mulheres correm o risco de infectar seus bebês ao } \\
\text { amamentá-los }^{(32-33)}\end{array}$ \\
\hline
\end{tabular}


Tabela 3 - Fatores relacionados à adesão à profilaxia da Transmissão Vertical do HIV e nexos com a vulnerabilidade no plano analítico programático. LILACS e MEDLINE, 1994-2010

\begin{tabular}{|c|c|}
\hline Fatores abordados & Fatores relacionados ao objeto de estudo \\
\hline Formação profissional & Formar profissionais para assistência especializada às pessoas ${ }^{(20)}$ \\
\hline Qualificação profissional & $\begin{array}{l}\text { Incluir nas qualificações temas como educação em saúde, alimentação infantil e } \\
\text { aconselhamento pré e pós-teste }{ }^{(11,26,29,34-35)}\end{array}$ \\
\hline $\begin{array}{l}\text { Qualidade do } \\
\text { atendimento nos } \\
\text { serviços de saúde }\end{array}$ & 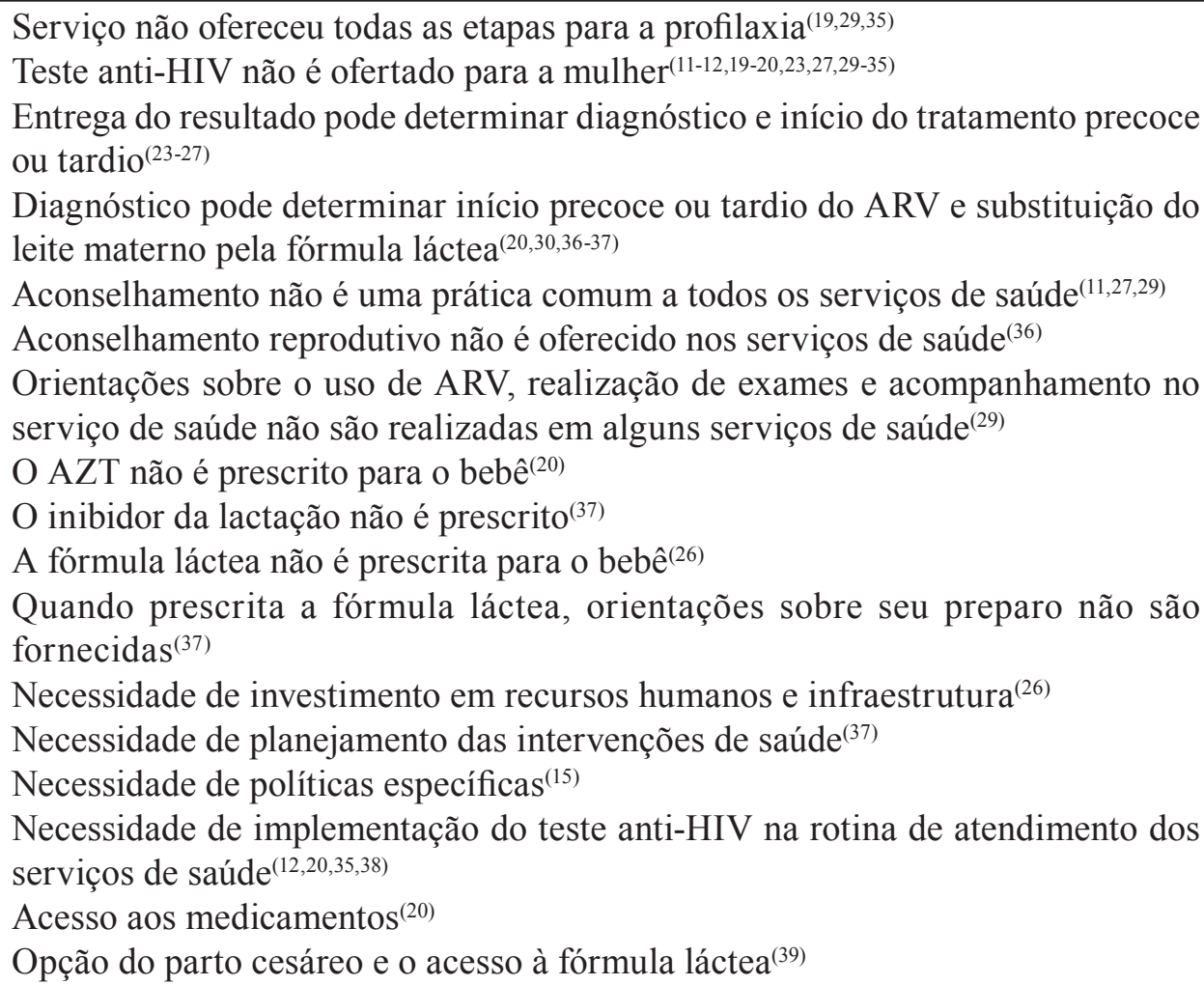 \\
\hline
\end{tabular}

\section{DISCUSSÃO}

Diante dos fatores de vulnerabilidade no plano individual, a maioria das mulheres aceita realizar o teste anti-HIV durante o pré-natal, pois este representa a possibilidade de proteção e cuidado com seu filho(40). Porém, algumas gestantes expressaram medo quanto ao teste, o que pode contribuir para a decisão de não realizá-lo. Esse sentimento pode ser minimizado por meio do acolhimento pelos profissionais, momento de serem esclarecidas para a superação de possíveis conflitos em decorrência da testagem e para a autopercepção de vulnerabilidade, que reflete na decisão autônoma ${ }^{(41-42)}$.

Quanto à aceitação do diagnóstico, esta não consiste em aceitar pacientemente a doença, envolve os valores culturais e a compreensão que a mulher e as pessoas à sua volta fazem acerca da doença ${ }^{(43)}$. A religião pode influenciar positivamente neste processo, uma vez que as algumas mulheres recorrem à fé como forma de se conformar e buscar forças ${ }^{(44)}$. Além disso, a gestação no contexto do HIV/aids pode provocar ambiguidade de sentimentos, permeados por culpa, medo, ansiedade e fé. Destes, a fé demonstra-se como apoio às mulheres e a crença na cura estimula à adesão ao tratamento ${ }^{(45)}$.

A oferta de antirretroviral ao bebê é relevante para eficácia da profilaxia, pois há redução da taxa de TV nos casos em que a mãe e a criança receberam intervenções, se comparados com os casos em que as crianças não receberam intervenções ${ }^{(46)}$.

A decisão das mulheres que têm HIV/aids de amamentar, ou não, sofre influência de fatores socioculturais. As mulheres têm vivências e experiências no que diz respeito à amamentação; demonstram estranheza, dor, dificuldade e tristeza por não poderem amamentar e escondem seu diagnóstico por receio do que os outros possam dizer ${ }^{(47)}$. A partir disso se pode pensar em estratégias para atenção às mulheres nesse contexto.

Uma das ferramentas para tal atenção está na educação em saúde como modos de ensino e aprendizagem, de compartilhar ideias e experiências, e de crescimento 
mútuo. Consiste num processo reflexivo e participativo, capaz de contribuir para a minimização de sofrimentos, trabalhar expectativas e emoções, além de promover cidadania e qualidade de vida ${ }^{(48)}$. E, ainda, a percepção de (in)vulnerabilidade que cada pessoa tem de si própria está posta como desafio na educação em saúde ${ }^{(41)}$.

Salienta-se a necessidade de investimento em ações educativas não só para a prevenção de novas infecções pelo HIV e a decisão reprodutiva, como também para adesão ao tratamento. Pessoas com níveis de escolaridade mais elevados apresentam maior aderência ao tratamento do que as com níveis de escolaridade mais baixos ${ }^{(49)}$. Além disso, evidencia-se que a baixa escolaridade das mulheres que têm HIV/aids se relaciona com a baixa adesão ao acompanhamento da sua condição clínica e obstétrica, a qual pode refletir na eficácia da profilaxia da $\mathrm{TV}^{(50)}$.

Outro fator que interfere na prevenção da TV diz respeito às condições socioeconômicas dessas mulheres. A fragilidade na prevenção está relacionada à amamentação no contexto do HIV/aids a qual, em condições socioeconômicas desfavoráveis, pode ser considerada além de uma decisão, uma condição alimentar de sobrevivência ${ }^{(51)}$. Além disso, renda e vínculo empregatício se relacionam à qualidade de vida das pessoas vivendo com HIV/aids, pois há preocupação com a saúde, preocupação financeira, questões relativas à medicação e satisfação com a vida ${ }^{(52)}$. Tais variáveis podem refletir nos cuidados com a profilaxia da TV.

Os fatores de vulnerabilidade nos planos individual e social implicam, diretamente, nos fatores de vulnerabilidade no plano programático. Dentre eles, pode-se destacar a necessidade de inclusão da temática HIV/aids nas políticas públicas e na formação dos profissionais de saúde, vislumbrando a qualidade da assistência prestada ${ }^{(50)}$.

Considerando a qualidade na assistência, salienta-se a necessidade de implementação de ações de educação permanente. As mulheres usuárias dos serviços de saúde reconhecem a relevância de serem atendidas por profissionais capacitados ${ }^{(53)}$, pois dessa forma as informações compartilhadas se tornam acessíveis, possibilitando romper com o ciclo de incompreensão e mito que permeia a aids entre as mulheres ${ }^{(54)}$.

Entende-se que a qualidade do atendimento nos serviços de saúde favorece a redução do coeficiente de mortalidade materna e da frequência de transmissão vertical do HIV. Dessa forma, salienta-se a exigência dos profissionais serem capacitados não só para oferecer o teste anti-HIV às gestantes, mas para envolver toda a comunidade em atividades de educação em saúde ${ }^{(41)}$.
Para eficácia das ações de prevenção e assistência é imprescindível a interlocução entre as políticas públicas de saúde para as mulheres, para as crianças e para o aleitamento materno ${ }^{(50)}$. Bem como a conformação de uma rede organizada, definindo-se as atribuições entre os níveis de atenção à saúde no âmbito do Sistema Único de Saúde visando garantir o acesso das gestantes, parturientes e recém-nascidos às mais recentes tecnologias de diagnóstico, controle e manejo da infecção pelo HIV ${ }^{(55)}$.

\section{CONSIDERAÇÕES FINAIS}

Partindo da análise das publicações científicas na temática sob a perspectiva da vulnerabilidade, compreende-se que os planos analíticos individual, social e programático pontuam fatores significativos na adesão à profilaxia da transmissão vertical do HIV.

No plano individual, destacam-se os fatores comportamentais relacionados às decisões que as mulheres tomam, as quais podem favorecer ou prejudicar a adesão à profilaxia e são influenciadas tanto pelos fatores sociais quanto pelos programáticos. A contribuição dos fatores sociais às decisões se refere ao acesso à informação sobre as questões que permeiam a profilaxia da transmissão vertical do HIV que as pessoas deveriam ter, mas nem sempre ocorre. Em meio ao avanço tecnológico e ampla divulgação de informações pela mídia, o quantitativo de pessoas que permanecem desconhecendo ou com conceitos desatualizados sobre o HIV/aids é significativo.

No plano programático, destaca-se o empenho governamental em efetivar as ações propostas pelas políticas públicas existentes, a fim de proporcionar assistência adequada e eficaz às pessoas que têm HIV/aids e a prevenção das pessoas não infectadas. Deparamo-nos com a falta de qualificação dos profissionais, com a necessidade de formação especializada para assistir a essa população, e de investimento na qualificação. E necessidade de melhorar a infraestrutura para a assistência às pessoas já infectadas, bem como a prevenção daquela não infectadas pelo HIV.

Diante disso, pode-se considerar que os planos de vulnerabilidade mantêm estreita relação entre si, pois, a partir da eficácia das ações propostas e desenvolvidas no plano programático, por meio de políticas públicas de atenção e prevenção, as informações sobre HIV/aids podem se tornar acessíveis à população. Diante dessa acessibilidade, as pessoas poderão tomar suas decisões de maneira informada, ou seja, fazerem sua escolha reprodutiva detendo o conhecimento necessário para seguir continuamente os cuidados para profilaxia da TV. 
Nesse sentido, destaca-se o enfermeiro como mediador entre os planos de vulnerabilidade, sendo capaz de promover espaços dialógicos nos serviços de saúde a fim de compartilhar com a população o conhecimento acerca do HIV/aids. Dessa forma, as pessoas têm acesso às informações e a possibilidade de as utilizarem, autonomamente, em prol da continuidade dos cuidados com sua saúde.

\section{REFERÊNCIAS}

1. Ministério da Saúde (BR). Secretaria de Vigilância em Saúde. Programa Nacional de DST e Aids. Boletim Epidemiológico Aids e DST, Brasília, 2010.

2. Connor EM, Sperling RS, Gelber R, Kiselev P, Scott $\mathrm{G}, \mathrm{O}$ 'Sullivan MJ, et al. Reducion of maternal-infant transmission of human immunodeficiency virus type 1 with zidovudine treatament. N Engl J Méd. 1994;331(18):1173-80.

3. Ministério da Saúde (BR). Secretaria de Vigilância em Saúde. Programa Nacional de DST e Aids. Recomendações para profilaxia da transmissão vertical do HIV e terapia antirretroviral em gestantes. Brasília, 2010.

4. Ministério da Saúde (BR). Aconselhamento em DST, HIV e Aids: diretrizes e procedimentos básicos. Coordenação Nacional de DST e Aids, 1998.

5. Padoin SMM, Paula CC, Ribeiro TP, Romanini RM, Ribeiro AC. Vulnerabilidade materno-infantil: fatores de (não) adesão à profilaxia da transmissão vertical do HIV. REM: rev. min. enferm. 2011;15(3):443-52.

6. Langendorf TF, Padoin SMM, Vieira LB, Landerdahl MC, Hoffmann IC. Rede de apoio de mulheres que têm HIV: implicações na profilaxia da transmissão vertical. DST - J Bras Doenças Sex Transm. 2011;23(1):16-22.

7. Brasil. Lei n. 7.498 de 25 de Junho de 1986. Dispõe sobre a Regulamentação do Exercício da Enfermagem e dá outras providencias. Diário Oficial da Republica Federativa do Brasil, Brasília, 25 de junho de 1986.

8. Mendes KDS, Silveira RCCP, Galvão CM. Revisão integrativa: método de pesquisa para a incorporação de evidências na saúde e na enfermagem. Texto Contexto Enferm. 2008;17(4):758-64.

9. Minayo MCS. O desafio do conhecimento: pesquisa qualitativa em saúde. São Paulo: Hucitec; 2007.
10. Calazans GJ, Saletti Filho HC, França Jr. I, Ayres JRCM. O conceito de vulnerabilidade. In: Padoin SMM, Paula CC, Schaurich D, Fontoura VA. Experiências interdisciplinares em AIDS: interfaces de uma epidemia. Santa Maria: UFSM. 2006. p.43-62.

11. Nichols SA, Bhatta MP, Lewis J, Vermund SH. Prenatal HIV counseling, testing, and antiretroviral prophylaxis by obstetric and family medicine providers in Alabama. Am J Med Sci. [Internet] 2002;324(6) [acesso em 10 nov 2011]. Disponível: http://www.ncbi.nlm.nih.gov/ pubmed/12495296

12. Rey D, Obadia Y, Carrieri MP, Moatti JP. HIV screening for pregnant women in south eastern France: evolution 1992-1994-1996. Eur J Obstet Gynecol Reprod Biol. [Internet] 1998;76(1) [acesso em 10 nov 2011]. Disponível: http://www.ncbi.nlm.nih.gov/ pubmed/9481538

13. Abiodun MO, Ijaiya MA, Aboyeji PA, Balogun OR. Acceptability of measures aimed at preventing motherto-child transmission of HIV among pregnant women. J Natl Med Assoc. [Internet] 2008;100(4) [acesso em 10 nov 2011]. Disponível: http://www.ncbi.nlm.nih.gov/ pubmed/18481479

14. Church JD, Omer SB, Guay LA, Huang W, Lidstrom $\mathrm{J}$, Musoke P, et al. Analysis of nevirapine (NVP) resistance in Ugandan infants who were HIV infected despite receiving single-Dose (SD) NVP versus SD NVP plus daily NVP up to 6 weeks of age to prevent HIV vertical transmission. J Infect Dis. [Internet] 2008;198(7) [acesso em 10 nov 2011]. Disponível: http:// www.ncbi.nlm.nih.gov/pubmed/18684096

15. García R, Prieto F, Carlos A, Rincón J, Caicedo S, Rey G. Reducción de la transmisión madre hijo del VIH en Colombia: dos años de experiencia nacional, 2003-2005. Bogotá: Biomédica. [Internet] 2005;25(4) [acesso em 10 nov 2011]. Disponível: http://www.scielo.org.co/pdf/bio/ v25n4/v25n4a15.pdf

16. Peltzer K, Mlambo G, Phaweni K. Factors determining prenatal HIV testing for prevention of mother to child transmission of HIV in Mpumalanga, South Africa. AIDS Behav. [Internet] 2010;14(5) [acesso em 10 nov 2011]. Disponível: http://www.ncbi.nlm.nih.gov/ pubmed/20049520

17. Carvalho FT, Piccinini CA. Maternidade em situação de infecção pelo HIV: um estudo sobre os sentimentos de gestantes. Interação em Psicologia. [Internet] 2006;10(2) [acesso em 10 nov 2011]. Disponível: http://ojs.c3sl.ufpr. br/ojs2/index.php/psicologia/article/viewArticle/7693 
18. Romanelli RMC, Kakehasi FM, Tavares MCT, Melo VH, Goulart LHF, Aguiar RALP, et al. Perfil das gestantes infectadas pelo HIV atendidas em pré-natal de alto risco de referência de Belo Horizonte. Rev. Bras. Saúde Matern. Infant. [Internet] 2006;6(3) [acesso em 10 nov 2011]. Disponível: http://www.scielo.br/scielo.php?script=sci arttext\&pid=S1519-38292006000300009\&lng=en\& nrm=iso ISSN 1519-3829. http://dx.doi.org/10.1590/ S1519-38292006000300009

19. Succi RCM. Mother-to-child transmission of HIV in Brazil during the years 2000 and 2001: results of a multi-centric study. Cad. Saúde Pública. [Internet] 2007;23(suppl 3) [acesso em 10 nov 2011]. Disponível: http://www.scielo.br/pdf/csp/v23s3/06.pdf

20. Turchi MD, Duarte LS, Martelli CMT. Mother-tochild transmission of HIV: risk factors and missed opportunities for prevention among pregnant women attending health services in Goiânia, Goiás State, Brazil. Cad. Saúde Pública. [Internet] 2007;23(suppl 3) [acesso em 10 nov 2011]. Disponível: http://www.scielo. br/scielo.php?script=sci_arttext\&pid=S0102-311X2007 001500007\&lng=en\&nrm=iso ISSN 0102-311X. http:// dx.doi.org/10.1590/S0102-311X2007001500007

21. Calvet GA, João EC, Nielsen-Saines K, Cunha CB, Menezes JA, D'Ippolito MM, et al. Trends in a cohort of HIV-infected pregnant women in Rio de Janeiro, 1996-2004. Rev. Bras. Epidemiol. [Internet] 2007;10(3) [acesso em 10 nov 2011]. Disponível: http://www.scielo. br/scielo.php?script $=$ sci_arttext\&pid=S1415-790X2007 000300004\&lng=en\&nrm=iso ISSN 1415-790X. http:// dx.doi.org/10.1590/S1415-790X2007000300004

22. Moura EL, Praça NS. Transmissão vertical do HIV: expectativas e ações da gestante soropositiva. Rev. Latino-Am. Enferm. [Internet] 2006;14(3) [acesso em 10 nov 2011]. Disponível: http://www.scielo.br/pdf/rlae/ v14n3/v14n3a15.pdf

23. Torres SR, Luz AMH. Gestante HIV+ e crianças expostas: estudo epidemiológico da notificação compulsória. Rev Gaúcha Enferm. [Internet] 2007;28(4) [acesso em 10 nov 2011]. Disponível: http://seer.ufrgs.br/ RevistaGauchadeEnfermagem/article/view/3111/1717

24. Iliff PJ, Piwoz EG, Tavengwa NV, Zunguza CD, Marinda ET, Nathoo KJ, et al. Early exclusive breastfeeding reduces the risk of postnatal HIV-1 transmission and increases HIV-free survival. AIDS. [Internet] 2005;19(7) [acesso em 10 nov 2011]. Disponível: http:// www.ncbi.nlm.nih.gov/pubmed/15821396

25. Israel-Ballard KA, Maternowska MC, Abrams BF,
Morrison P, Chitibura L, Chipato T, et al. Acceptability of heat treating breast milk to prevent mother-to-child transmission of human immunodeficiency virus in Zimbabwe: a qualitative study. J Hum Lact. 2006; 22(1):48-60.

26. Söderlund N, Zwi K, Kinghorn A, Gray G. Prevention of vertical transmission of HIV: analysis of cost effectiveness of options available in South Africa. BMJ. [Internet] 1999;18(7199) [acesso em 10 nov 2011]. Disponível: http://www.ncbi.nlm.nih.gov/pmc/articles/ PMC28142/

27. David PRS, Salomão MLM. Transmissão maternoinfantil do HIV em São José do Rio Preto em 2001 e 2002. Arq. Ciênc. Saúde. [Internet] 2006;0613(2) [acesso em 10 nov 2011]. Disponível: http://www. cienciasdasaude.famerp.br/racs_ol/vol-13-2/01-ID\%20 114.pdf

28. Mahmoud MM, Nasr AM, Gassmelseed DE, Abdalelhafiz MA, Elsheikh MA, Adam I. Knowledge and attitude toward HIV voluntary counseling and testing services among pregnant women attending an antenatal clinic in Sudan. J Med Virol. [Internet] 2007;79(5) [acesso em 10 nov 2011]. Disponível: http://www.ncbi.nlm.nih.gov/ pubmed/17385672

29. Cavalcante MS, Ramos Junior AN, Silva TMJ, Pontes LRSK. Transmissão vertical do HIV em Fortaleza: revelando a situação epidemiológica em uma capital do nordeste. Rev Bras Ginecol Obstet. [Internet] 2004;26(2) [acesso em 10 nov 2011]. Disponível: http://www.scielo.br/scielo.php?script=sci arttext\&pid $=$ S0100-72032004000200008\&lng=en \& nrm=iso ISSN 0100-7203. http://dx.doi.org/10.1590/ S0100-72032004000200008

30. Piwoz EG, Iliff PJ, Tavengwa N, Gavin L, Marinda E, Lunney K, et al. An education and counseling program for preventing breast-feeding-associated HIV transmission in Zimbabwe: design and impact on maternal knowledge and behavior. J Nutr. [Internet] 2005;135(4) [acesso em 10 nov 2011]. Disponível: http:// www.ncbi.nlm.nih.gov/pubmed/15795468

31. Ho CF, Loke AY. Pregnant women's decisions on antenatal HIV screening in Hong Kong. AIDS care. [Internet] 2003;15(6) [acesso em 10 nov 2011]. Disponível: http://www.ncbi.nlm.nih.gov/pubmed/14617503

32. Coutsoudis A. Influence of infant feeding patterns on early mother-to-child transmission of HIV-1 in Durban, South Africa: a prospective cohort study. The Lancet. [Internet] 1999;354(9177) [acesso em 10

Cogitare Enferm. 2012 Out/Dez; 17(4):758-66 
nov 2011].Disponível: http://www.ncbi.nlm.nih.gov/ pubmed/11131697

33. Bentley ME, Corneli AL, Piwoz E, Moses A, Nkhoma $\mathrm{J}$, Tohill BC, et al. Perceptions of the role of maternal nutrition in HIV-positive breast-feeding women in Malawi. J Nutr. [Internet] 2005;135(4) [acesso em 10 nov 2011]. Disponível: http://www.ncbi.nlm.nih.gov/ pubmed/15795467

34. Maturana AP, Rizzo CV, Vasquez DF, Cavalheiro N, Holzer S, Morais VS. Avaliação da assistência ao parto em gestantes infectadas pelo HIV. Arq. méd. ABC. [Internet] 2007;32(1) [acesso em 10 nov 2011]. Disponível: http://bases.bireme.br/cgi-bin/wxislind.exe/ iah/online/?IsisScript $=$ iah/iah.xis\&src $=$ google \&base $=$ LILACS\&lang $=$ p\&nextAction $=\operatorname{lnk} \& \operatorname{exprSearch}=4554$ 73\&indexSearch=ID

35. Lemos LMD, Gurgel RQ, Dal Fabbro AL. Prevalência da infecção por HIV em parturientes de maternidades vinculadas ao SUS. Rev Bras Ginecol Obstet. [Internet] 2005;27(1) [acesso em 10 nov 2011]. Disponível: http://www.scielo.br/scielo.php?script=sci arttext\&pid=S0100-72032005000100007\&lng=en\& nrm=iso ISSN 0100-7203. http://dx.doi.org/10.1590/ S0100-72032005000100007

36. McConnell M, Bakaki P, Eure C, Mubiru M, Bagenda D, Downing R, et al. Effectiveness of repeat singledose nevirapine for prevention of mother-to-child transmission of HIV-1 in repeat pregnancies in Uganda. J Acquir Immune Defic Syndr. [Internet] 2007;46(3) [acesso em 10 nov 2011]. Disponível: http://www.ncbi. nlm.nih.gov/pubmed/18167645

37. Barroso LMM, Galvão MTG. Avaliação de atendimento prestado por profissionais de saúde a puérperas com HIV/AIDS. Texto Contexto Enferm. [Internet] 2007;16(3) [acesso em 10 nov 2011]. Disponível: http://www.scielo.br/scielo.php?script=sci arttext\&pid=S0104-07072007000300012\&lng=en\& nrm=iso ISSN 0104-0707. http://dx.doi.org/10.1590/ S0104-07072007000300012

38. Fernandes RCSC, Araújo LC, Medina-Acosta E. O desafio da prevenção da transmissão vertical do HIV no Município de Campos dos Goytacazes, Rio de Janeiro, Brasil. Cad. Saúde Pública. [Internet] 2005;21(4) [acesso em 10 nov 2011]. Disponível: http://www.scielo.br/ scielo.php?script $=$ sci_arttext\&pid=S0102-311X20050 00400017\&lng=en\&nrm=iso ISSN 0102-311X. http:// dx.doi.org/10.1590/S0102-311X2005000400017

39. Tschudin S, Steimann S, Bitzer J, Hösli I, Holzgreve W,
Elzi L, et al. Round-table multidisciplinary counselling of couples with HIV prior to assisted reproduction. Reprod Biomed Online. [Internet] 2008;17(2) [acesso em 10 nov 2011]. Disponível: http://www.ncbi.nlm.nih. gov/pubmed/18681989

40. Silva RMO, Araújo CLF, Paz FMT. A realização do teste anti-HIV no pré-natal: os significados para a gestante. Esc. Anna Nery. [Internet] 2008;12(4) [acesso em 10 nov 2011]. Disponível: http://www.scielo.br/scielo.php?script=sci arttext\&pid=S1414-81452008000400004\&lng=en\& nrm=iso ISSN 1414-8145. http://dx.doi.org/10.1590/ S1414-81452008000400004

41. Matos SD, Baptista RS, França ISX, Medeiros FAL, Brito VRS. Conhecimento das gestantes atendidas nos serviços de pré-natal acerca do teste anti-HIV. REME: rev. min. enferm. 2009;10(2):122-30.

42. Barroso LMM, Soares AP, Soares BC, Araújo MAL, Silva DMA. Percepção dos usuários acerca do aconselhamento pré-teste anti-HIV em uma unidade de referência em Fortaleza, eará. Revista Espaço para a Saúde. 2010;1:23-29.

43. Costa DAM, Zago MMF, Medeiros M. Experiência da adesão ao tratamento entre mulheres com Vírus da Imunodeficiência Humana. Acta Paul. Enferm 2009;22(5):631-7.

44. Martins JT, Garanhani ML, Robazzi MLC, Santos WC. Significados de qualidade de vida para mulheres convivendo com AIDS. Rev Gaúcha Enferm. 2008;29(4):619-25.

45. Padoin SMM, Paula CC, Ribeiro TP, Romanini RM, Ribeiro AC. Vulnerabilidade materno-infantil: fatores de (não) adesão à profilaxia da transmissão vertical do HIV. REME: rev. min. enferm.2011;15(3):443-52.

46. Torpey K, Kasonde P, Kabaso M, Weaver MA, Bryan $\mathrm{G}$, Mukonka V, et al. Reducing pediatric HIV infection: estimating mother-to-child transmission rates in a program setting in Zambia. J Acquir Immune Defic Syndr. 2010;54(4):415-22.

47. Padoin SMM, Terra MG, Souza IEO. O mundo da vida da mulher que têm HIV/AIDS no cotidiano da (im)possibilidade de amamentar. Esc. Anna Nery. 2011;15(1):13-21.

48. Pereira AV, Vieira AL, Filho AA. Grupos de educação em saúde: aprendizagem permanente com pessoas soropositivas para o HIV. Trab. Educ. Saúde. 2011;9(1)2541. 
49. Ilias M, Carandina L, Marin MJS. Adesão à terapia antirretroviral de portadores do vírus da imunodeficiência humana atendidos em um ambulatório da cidade de Marília, São Paulo. Revista baiana de saúde pública. 2011;35(2)471-84.

50. Langendorf TF, Padoin SMM, Vieira LB, Mutti CF. Gestantes que tem HIV/aids no contexto da transmissão vertical: visibilidade da produção cientifica nacional na área da saúde. Rev. pesqui. cuid. fundam. 2011;3(3):2109-25.

51. Gewa CA, Oguttu M, Savaglio L. Determinants of early child-feeding practices among HIV-infected and noninfected mothers in rural Kenya. J Hum Lact. 2011;27(3):239-49.

52. Reis RK, Santos CB, Dantas RAS, Gir E. Qualidade de vida, aspectos sociodemográficos e de sexualidade de pessoas vivendo com HIV/AIDS. Texto Contexto Enferm. 2011;20(3): 365-75.

53. Pisani JP, Zoboli ELCP. Doenças sexualmente transmissíveis: preservar a confidencialidade do marido ou proteger a saúde da mulher? Cogitare enferm. 2009; 14(3):476-83.

54. Henriques MERM, Lima EAR. Mulheres expostas ao HIV/AIDS: promovendo qualidade de vida na atenção básica. Rev. Eletr. Enf. 2009;11(4):952-63.

55. Ministério da Saúde (BR). Secretaria de Vigilância em Saúde Programa Nacional de DST e Aids. Protocolo para a prevenção de transmissão vertical de HIV e sífilis. Manual de Bolso. Brasília; 2007. 